\title{
(2) OPEN ACCESS \\ Hospital leadership perspectives on the value of the 3 Wishes Project: a qualitative study
}

\author{
Marilyn Swinton, ${ }^{1}$ Meredith Vanstone, ${ }^{2}$ Peter Phung, ${ }^{3}$ Thanh $\mathrm{H}$ Neville, ${ }^{4}$ \\ Alyson Takaoka (0) , ${ }^{1}$ Orla M Smith, ${ }^{5}$ Andrew Baker, ${ }^{5}$ Allana LeBlanc, ${ }^{6}$ Denise Foster, ${ }^{6}$ \\ Vinay Dhingra, ${ }^{7}$ France J Clarke, ${ }^{1}$ Neala Hoad ${ }_{1}^{8}$ Anne Woods, ${ }^{2,9}$ Anne Boyle, ${ }^{2,9}$ \\ Feli Toledo, ${ }^{10}$ Deborah J Cook ${ }^{1,8,11}$
}

- Additional material is published online only. To view, please visit the journal online (http://dx.doi.org/10.1136/ leader-2020-000302).

For numbered affiliations see end of article.

Correspondence to Dr Deborah I Cook,

Departments of Medicine and Health Research Methods,

Evidence and Impact, McMaster University, Hamilton, ON L8N 3Z5, Canada;

debcook@mcmaster.ca

Received 28 May 2020 Revised 14 August 2020 Accepted 24 August 2020 Published Online First 27 October 2020

\section{ABSTRACT \\ Background Healthcare organisations are increasingly interested in improving the work life of their employees. By encouraging individualised acts of compassion for dying patients and their families, the 3 Wishes Project (3WP) has been shown to ease grief for both families and clinicians.}

Purpose The objective of this study was to explore the perspectives of hospital leaders on the value of the 3WP to the hospital and how decisions are made about which programmes to support.

Methods We conducted semistructured interviews with 20 hospital leaders in four North American institutions. Transcripts were analysed using qualitative content analysis.

Results Interviews with 12 clinical managers and 8 senior administrators identified the institutional value of the 3WP as improving patient and family experiences, enhancing staff morale, translating institutional mission and values into front-line practice, and creating positive public relations. Hospital leaders acknowledged potentia resource challenges, including staff time, space to store supplies and funds to purchase items for some wishes. However, citing stories they had heard from families and staff, hospital leaders shared their view of how their decisions about the value of clinical programmes extend beyond quantifiable outcomes.

Conclusions When reflecting on this personalised palliative care programme, hospital leaders described how inspiring narratives promoted institutional values in ways that are difficult to measure quantitatively. Leaders underscored the need to balance the value that a programme brings with the resources it requires, stating how different types of evidence influence their support of new programmes.

Trial registration number NCT04147169.

\section{BACKGROUND}

Many healthcare organisations are guided by the Institute for Healthcare Improvement's (IHI) 'Triple Aim': improving population health, improving the experience of care and reducing costs. ${ }^{1}$ The 'Quadruple Aim', introduced in 2014, includes 'improving work life'. ${ }^{2}$ The fourth aim speaks to engaged employees deriving a sense of meaning, or even joy, in their work. Meaning refers to the sense of importance of daily work, and joy is the feeling of fulfilment resulting from that work. ${ }^{4-7}$

A hospital culture that likens healthcare to a business transaction between patients and providers may lead to clinician dissatisfaction and burn-out. ${ }^{89}$ Burn-out is associated with negative clinician consequences, including depression, suicidality and substance abuse, ${ }^{10-14}$ patient safety concerns, increased staff turnover, and decreased productivity. ${ }^{15}$ Consequently, some hospital leaders are motivated to make work meaningful for employees. Literature on this topic is sparse, and it can be challenging for leaders to identify and support systemlevel programmes that increase meaning or joy from work.?

One programme with potential to achieve this objective is the 3 Wishes Project (3WP). The $3 \mathrm{WP}$ is an end-of-life intervention designed to encourage acts of compassion from a systems-level perspective, yet is rooted in personalised human interactions. In the $3 \mathrm{WP}$, patients and families were invited to participate if the estimated probability of the patient's death was greater than $95 \%$ or after a decision had been made to withdraw life-sustaining technology. Clinicians elicit and implement wishes for dying patients and families, which allows for individualised end-of-life care that honours the dying person's dignity. Wishes may include playing the patient's favourite music, a trip outside, personalising the room or facilitating celebrations. For the family, the $3 \mathrm{WP}$ helps to create enduring positive memories. For clinicians, it fosters interprofessional collaboration. ${ }^{16}$ Beginning in 2013 as a single-centre intensive care unit (ICU) demonstration project at St Joseph's Healthcare Hamilton, Ontario, Canada, the 3WP has expanded to several sites. ${ }^{1617}$ A recent multicentre evaluation found the $3 \mathrm{WP}$ to be a meaningful, transferrable, sustainable and affordable programme. ${ }^{17}$

In this analysis, our objective was to explore the perspectives of hospital leaders on the value of the $3 \mathrm{WP}$ to the hospital and to understand their considerations when deciding to support specific programmes.

\section{METHODS}

Setting

This study was conducted in four tertiary-care ICUs involved in a multicentre 3WP implementation study ${ }^{17}$ (table 1 ). Interviews with 20 hospital leaders about this palliative care programme are the foci of this report. At the time of these interviews the $3 \mathrm{WP}$ had been implemented for variable periods of time across sites, ranging from 10 months to more than 5 years. 
Table 1 Site characteristics

\begin{tabular}{|c|c|c|c|c|c|c|}
\hline $\begin{array}{l}\text { Healthcare } \\
\text { institution }\end{array}$ & $\begin{array}{l}\text { Patient } \\
\text { populations }\end{array}$ & ICU beds (n) & $\begin{array}{l}\text { Total patients } \\
\text { enrolled }(\mathrm{n}) \text { and total } \\
\text { wishes implemented } \\
\text { (n) }\end{array}$ & $\begin{array}{l}\text { Duration of 3WP } \\
\text { implementation } \\
\text { at time of data } \\
\text { collection }\end{array}$ & Mission & Values \\
\hline Site 1 & Medical, surgical & 23 & $\begin{array}{l}369 \text { patients } \\
1982 \text { wishes }\end{array}$ & 5.5 years & $\begin{array}{l}\text { Living the legacy: Compassionate } \\
\text { care. Faith. Discovery. }\end{array}$ & $\begin{array}{l}\text { Dignity, respect, service, justice, responsibility, } \\
\text { enquiry. }\end{array}$ \\
\hline Site 2 & $\begin{array}{l}\text { Trauma and } \\
\text { neurosurgical } \\
\text { Medical and } \\
\text { surgical }\end{array}$ & $\begin{array}{l}19 \\
24\end{array}$ & $\begin{array}{l}134 \text { patients } \\
554 \text { wishes }\end{array}$ & 1 year, 3 months & $\begin{array}{l}\text { Catholic healthcare organisation } \\
\text { providing compassionate physical, } \\
\text { emotional and spiritual care to all } \\
\text { in need. We advance excellence } \\
\text { in healthcare through world-class } \\
\text { education, research and innovation. }\end{array}$ & $\begin{array}{l}\text { Human dignity, compassion, excellence, } \\
\text { community, inclusivity. }\end{array}$ \\
\hline Site 3 & $\begin{array}{l}\text { Medical, surgical, } \\
\text { trauma }\end{array}$ & 30 & $\begin{array}{l}94 \text { patients } \\
295 \text { wishes }\end{array}$ & 1 year, 3 months & $\begin{array}{l}\text { Come together as one collective } \\
\text { team to deliver an exceptional care } \\
\text { experience for all. }\end{array}$ & $\begin{array}{l}\text { We care for everyone, we are always learning, we } \\
\text { strive for better results. }\end{array}$ \\
\hline Site 4 & Medical & 24 & $\begin{array}{l}133 \text { patients } \\
494 \text { wishes }\end{array}$ & 10 months & $\begin{array}{l}\text { To deliver leading-edge patient care, } \\
\text { research and education. }\end{array}$ & $\begin{array}{l}\text { Ensure integrity, compassion, respect, teamwork, } \\
\text { excellence and discovery in the work we do daily. }\end{array}$ \\
\hline
\end{tabular}

The table describes the characteristics of participating hospitals and ICUs.

ICU, intensive care unit; 3WP, 3 Wishes Project.

\section{Methodology}

We found a pragmatist philosophical approach, focusing on participant experiences to understand 'what works' about the phenomenon under study, as an appropriate approach. ${ }^{18}$ Qualitative description methodology allowed a full description of participant experiences in their own words, with little abstraction or interpretive inference. ${ }^{19} 20$

\section{Interview participants}

Each centre identified five clinical managers or senior administrators to invite for interviews. Managers were defined as individuals who had a direct role in managing clinical staff. Administrators held a senior position at the institution, to whom clinical managers reported. We designed a purposive sampling strategy in a focused effort to recruit a diverse sample consisting of managers and administrators with distinct roles and different types of exposure to the $3 \mathrm{WP}$ over variable periods of time across four centres. Not all participants had detailed knowledge of $3 \mathrm{WP}$, but each was aware of it in a capacity relevant to their role. Leaders were invited to participate in a semistructured interview conducted by members of the research team who were familiar with the $3 \mathrm{WP}$, two of whom were physicians at the institution where interviews were conducted. Two interviewers (MS, MV) were qualitative researchers not known to participants. The interview guide is shown in online supplemental appendix 1.

Interview participants provided written informed consent. Dying patients and/or their family members provided verbal consent to participate in the $3 \mathrm{WP}$.

\section{Analysis}

Interviews were digitally recorded, transcribed and de-identified. Transcripts were analysed using conventional content analysis, ${ }^{21}$ applying inductive coding to generate meaningful clusters for concept development as part of a qualitative descriptive approach. $^{22}$ Analysis required a staged process. First, the lead analyst completed line-by-line open coding to condense and summarise four transcripts from three sites. By looking across these descriptive codes for trends, patterns, relationships and structures of communication, we developed a preliminary list of categories and subcodes, which was further discussed and refined by consensus at a meeting with three members of the research team, who had read the transcripts. ${ }^{23}$ The remaining transcripts were then coded to this schema by three research team members, and the schema was refined, expanded and adapted to accommodate the new data. After this process, the three research team members organised the codes into meaningful categories based on the code relationships. In this process, 'meaningful' did not simply mean prevalent but also illuminating, emphasised as important by the participant, unique, relevant or clearly expressed. The categories of codes were organised into higher level clusters. ${ }^{24}$ All decisions related to the coding and analysis process were recorded in a study audit trail. ${ }^{25}$ NVivo V.11 (QSR International) was used for data management and coding. Data saturation was confirmed after 20 interviews when no further concepts were elucidated.

\section{RESULTS}

\section{Interview participants}

All invited hospital leaders completed an interview; 19 interviews were conducted in person and 1 by telephone between April 2017 and November 2018. The sample included 12 managers and 8 administrators; $35 \%$ were female, $40 \%$ had some clinical involvement with the $3 \mathrm{WP}$, and 30\% were involved in the initial decision to implement the 3 WP locally (table 2).

\section{Main findings}

Hospital leaders consistently reported that the 3WP brought value to patients, families and clinical staff. This was aligned with each hospital's institutional mission, vision and/or values (table 1), having salutary effects on relationships both within and outside of the institution. We did not elicit negative impressions of the programme in our interviews. When making decisions to implement or support programmes such as $3 \mathrm{WP}$, leaders referred to the need to balance resources and value, and conceptualised value beyond quantifiable outcomes (figure 1).

\section{Value of the programme to the hospital}

The value of the $3 \mathrm{WP}$ was described as based on the contribution it made to the experiences of patients, families and staff in a way that aligned with the institutional mission, reflecting internal worth to the hospital and external value to the public.

Interviewees emphasised the importance of a programme that created value for patients and families. These leaders described their perception that the $3 \mathrm{WP}$ effectively configures care such that "the patient gets control, dignity, and choice" (Chief Nursing Executive). 


\begin{tabular}{|c|c|c|c|}
\hline Title/role & Role & $\begin{array}{l}\text { Clinical } \\
\text { involvement with } \\
\text { 3WP }\end{array}$ & $\begin{array}{l}\text { Involvement in 3WP } \\
\text { implementation } \\
\text { decision }\end{array}$ \\
\hline Chief executive officer & Administrator & None & No \\
\hline Chief medical officer & Administrator & None & No \\
\hline Chief medical officer & Administrator & None & No \\
\hline Chief medical officer & Administrator & None & No \\
\hline Chief nursing executive & Administrator & None & No \\
\hline $\begin{array}{l}\text { Chief, pulmonary and } \\
\text { critical care division }\end{array}$ & Administrator & None & No \\
\hline $\begin{array}{l}\text { Clinical programme } \\
\text { director }\end{array}$ & Administrator & None & No \\
\hline $\begin{array}{l}\text { Operations director, } \\
\text { acute care }\end{array}$ & Administrator & None & Yes \\
\hline $\begin{array}{l}\text { Senior medical director, } \\
\text { acute care }\end{array}$ & Administrator & $\begin{array}{l}\text { Direct clinical } \\
\text { involvement }\end{array}$ & No \\
\hline Chief of medicine & Manager & $\begin{array}{l}\text { Indirect clinical } \\
\text { involvement }\end{array}$ & No \\
\hline Chief of staff & Manager & None & No \\
\hline Clinical manager, ICU & Manager & None & No \\
\hline $\begin{array}{l}\text { Clinical nurse manager, } \\
\text { ICU }\end{array}$ & Manager & $\begin{array}{l}\text { Indirect clinical } \\
\text { involvement }\end{array}$ & Yes \\
\hline $\begin{array}{l}\text { Manager, clinical services } \\
\text { (including ICU) }\end{array}$ & Manager & $\begin{array}{l}\text { Indirect clinical } \\
\text { involvement }\end{array}$ & Yes \\
\hline $\begin{array}{l}\text { Chief, department of } \\
\text { critical care }\end{array}$ & Manager & $\begin{array}{l}\text { Direct clinical } \\
\text { involvement }\end{array}$ & Yes \\
\hline Medical director, ICU & Manager & $\begin{array}{l}\text { Direct clinical } \\
\text { involvement }\end{array}$ & Yes \\
\hline $\begin{array}{l}\text { Medical director, step } \\
\text { down unit }\end{array}$ & Manager & $\begin{array}{l}\text { Direct clinical } \\
\text { involvement }\end{array}$ & No \\
\hline $\begin{array}{l}\text { Medical director, quality } \\
\text { for ICU }\end{array}$ & Manager & $\begin{array}{l}\text { Direct clinical } \\
\text { involvement }\end{array}$ & Yes \\
\hline $\begin{array}{l}\text { Director, spiritual care } \\
\text { department }\end{array}$ & Manager & None & No \\
\hline $\begin{array}{l}\text { Director, hospital } \\
\text { volunteer services }\end{array}$ & Manager & None & No \\
\hline
\end{tabular}

The table outlines the characteristics of hospital leaders we interviewed.

ICU, intensive care unit; 3WP, 3 Wishes Project.

\section{Value to patients and families}

Participants recognised that the non-medical aspects of care often determine the patient and family hospital experience. Sharing a story about a patient whose final wish was to have doughnuts from a specific store, a medical director for quality reflected:

Out of all the stuff that we did for him in the unit...he couldn't stop talking about the doughnuts. It's like that was the pinnacle of the healthcare was so good that [staff] went out of their way to bring him doughnuts....I think in some ways, people expect the IV, the pain, the medications, the fluids, ... but they don't expect somebody to go out of their way to [do] human acts of kindness. (Medical Director, Quality)

Multiple respondents noted that "patient-centered care is such a big thing and patient experience has really become a huge focal point in all of healthcare" (Chief Medical Officer). As leaders who typically hear about the best and worst experiences in their organisation, several participants recognised that patient and family experience is often about interaction with staff: "Most complaints aren't really around sort of the technical aspect of care. It's how you made them feel, right?" (Clinical Programme Director).

\section{Value to clinicians}

Hospital leaders indicated that the 3 WP contributed to clinicians' professional lives by increasing morale and creating
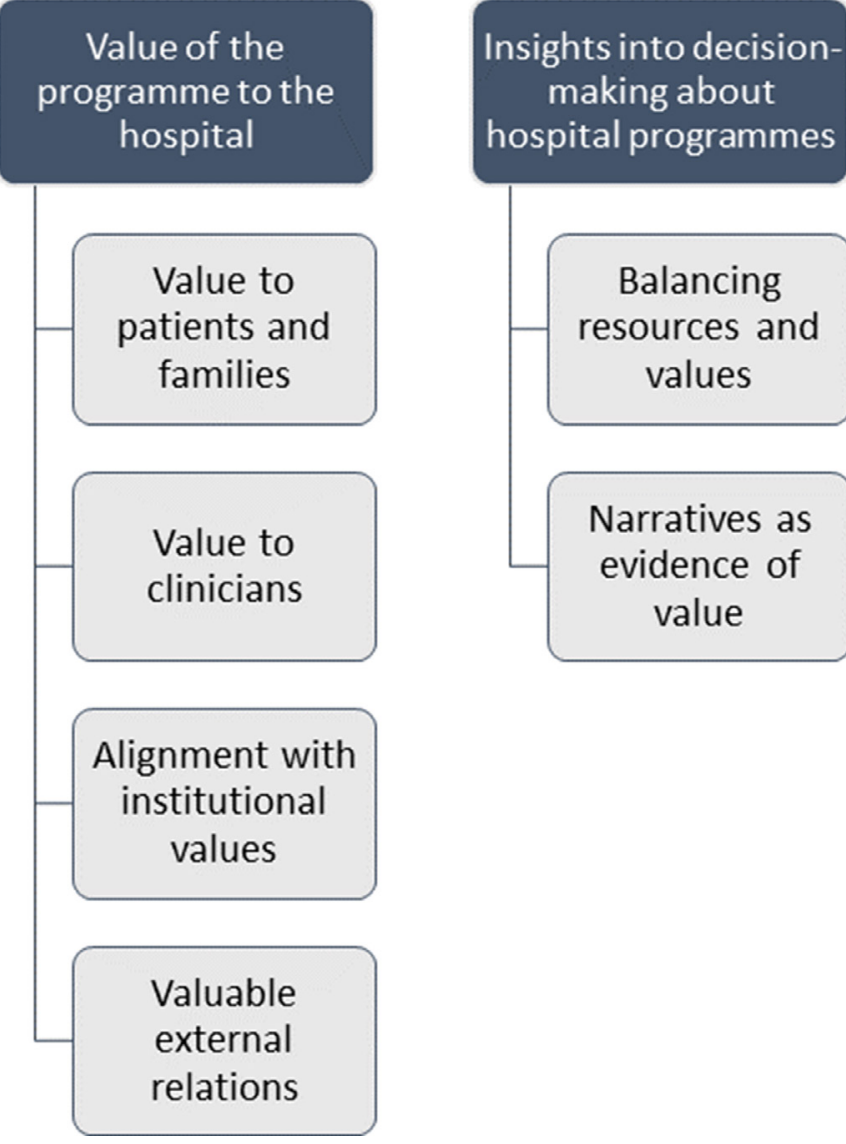

Figure 1 Main findings: 'value of the programme to the hospital' and 'insights into decision-making about hospital programmes', and their respective subthemes.

supportive relationships: "If you want an exercise or a project that promotes team building, this is it. It boosts morale in the unit" (Manager of Clinical Services). This was understood as important given the emotional toll of caring for dying patients and their families: "I think it would help them process all these deaths that they see...You're going to bear witness to the bad stuff and you're going to bear witness to the good stuff so, I think it balances out the bad with... what we can do to help" (Clinical Nurse Manager).

Leaders also expressed that the $3 \mathrm{WP}$ had a positive impact on the culture of the ICU, and staff recruitment and retention.

You can't deny the value that something like that brings to changing the culture within an organization for the staff. If you did it for no other reason, it would be for retention, it would be for burnout, it would be for...mitigating against all of those things. It really has a very positive staff effect. (Senior Medical Director, Acute Care)

Leaders were aware of challenges such as staff burn-out and attrition. The 3 WP helped create a supportive, collegial atmosphere: "[The 3WP] mitigates the sense of not belonging, and it mitigates the disconnectedness. It mitigates the stress..., and does bring people together" (Senior Medical Director, Acute Care). By highlighting the meaningfulness and purpose of clinical work, the $3 \mathrm{WP}$ was perceived to offer a renewed sense of vocation for staff: "The joy in the workplace comes from the reciprocity to say...'I feel that I have a greater purpose and meaning in what I do"” (Chief Medical Information Officer). 


\section{Alignment with institutional values}

Managers and administrators maintained that the $3 \mathrm{WP}$ also had value at the organisational level because it assisted the institution with meeting its mission and values.

Across sites, hospital leaders considered the $3 \mathrm{WP}$ as "completely aligned to our mission and values...[the $3 \mathrm{WP}$ ] is one of the banner projects you could stand up and say is one of the things that's so obviously aligned" (Chief of Staff).

The 3WP was widely viewed as providing a concrete way that clinicians can engage with institutional and professional priorities such as patient-centred care: "The very act of being prepared to try to meet these wishes sends a message to the patient and family that you consider them important" (Chief of Medicine).

Communicating commitment to institutional goals was important to leaders; they wanted to support programmes that explicitly illustrated these priorities to stakeholders and the community: "[3WP] is a program that allows [hospital name] to fulfill that mission of really delivering that compassionate quality care with acts of kindness. I think it is such a demonstrative way to really show how we care about the patients and the families" (Chief Executive Officer).

\section{Valuable external relations}

The potential of positively influencing other groups affiliated with the healthcare organisation was important to these leaders. Reflecting on how the $3 \mathrm{WP}$ spread from one institution to another in a neighbouring community, one chief of staff described how implementing the 3WP at one hospital "helps [the second hospital] because we're getting people that are elevating the bar....more knowledge, more retention, recruitment of staff, more happiness...it's a good, terrific thing" (Chief of Staff).

A consistent theme was demonstrating institutional priorities to groups outside the hospital. 3WP was a way to develop positive public relations in the broader community: "It's one way that we can really go above and beyond that helps differentiate ourselves from just other healthcare providers" (Chief Executive Officer). Each site was invested in sharing the $3 \mathrm{WP}$ as a quality of care initiative in their organisation with others:

Projects like this that spread and get presented and get published are very important to our reputation...not that we want to walk about with a big reputation, but that big reputation feeds the mission that we're on...It's really important to have that reputation because good things come from a good reputation. (Chief of Staff)

Although positive relations with the public were important, participants were careful to describe that these were not a goal or an end in themselves:

I think when anything that improves the public view of [hospital name], it's a good thing...indirectly so. The public relations thing I think is a little tricky. We're not doing this to get quote 'good publicity'. We're doing it because it's the right thing to do for our patients and secondarily for our staff. If they want to put it on social media...I think that reflects very positively on the institution. But... it could have the potential of being seen as a public relations quote 'gimmick', which isn't our drive at all. (Chief Medical Officer)

\section{Insights into decision-making about hospital programmes}

When speaking generally about how they make decisions about whether or not to support new programmes, hospital leaders discussed the need to balance the value of a programme with the resources it requires. Managers and administrators acknowledged that while their views about the $3 \mathrm{WP}$ were uniformly positive, its value was difficult to quantify. They described that for the modest resources required, the $3 \mathrm{WP}$ was well in line with the value it brought.

\section{Balancing resources and value}

In each hospital, the requirements for the $3 \mathrm{WP}$ were described as minimal, including modest staff time while on shift, minimal funds to purchase items for some wishes, and storage. A senior administrator at one hospital discussed the programme's requisite resources and return on investment in the context of the current economic climate:

Some of the other concerns for a project - not for this project, but for other projects that get brought to me - it's just how can we sustain it and are we getting enough benefit for the financial money? There's a lot of anxiety about healthcare reform and so everybody is trying to be lean and trying to be cost-cutting, but I think this [the 3WP] is one of those things that you're able to do a lot for very little. (Chief Medical Officer)

A medical director shared the trade-offs of resource requirements and value conferred by the $3 \mathrm{WP}$ :

It's been a very positive experience with very little downside. Low cost. Easy to implement. Quite impressive gratification from many of the staff members and the recipients, which in this case, are patients' families. So, for all those reasons, it seems like, to me, quite a win, win, win. (Medical Director ICU)

\section{Narratives as evidence of value}

When conceptualising value, managers and administrators described the role of different forms of evidence in their decision-making: "When it comes to something like the $3 \mathrm{WP}, \mathrm{I}$ don't think you need a randomized controlled trial to tell you that it's the right thing. Sometimes you just know it's the right thing to do" (Senior Medical Director).

This view was consistent across sites, with study participants acknowledging the difficulty of measuring the impact of $3 \mathrm{WP}$, but supporting it regardless: "Sometimes teasing out that you actually made an impact is hard. And there are just some things that are so intuitively obvious, ...I'm going to be hard pressed not to say this [the $3 \mathrm{WP}$ ] is the right thing to do" (Chief of Staff).

The willingness to accept stories as evidence of value may be related to the programme's emphasis on patient dignity:

The thing about the 3 Wishes is that it speaks to the human side of death as opposed to the machine side of death. I know there is all sorts of science behind all the...projects that are brought forth. But I think this one...[needs] less 'data collection', so it's...offering our support through, you know...novel, unique...ways of supporting families while their loved one is dying. (Clinical Nurse Manager, ICU)

When asked to describe how they concluded that the $3 \mathrm{WP}$ was beneficial and important, many hospital leaders told us about the influence of stories they heard:

I agree that we need evidence to implement new projects...But, like I said, I remember hearing a presentation of it having been implemented somewhere else and just seeing examples of things that had been done with families. That was all the evidence I needed... to hear the stories that...these good things had happened... There was no further need for evidence. (Clinical Manager, ICU)

\section{DISCUSSION}

Clinical managers and senior administrators in hospitals implementing the 3WP consistently viewed its value through the creation of positive experiences for patients, families and 
clinicians. By serving each of these stakeholders, hospital leaders described the $3 \mathrm{WP}$ as aligning with institutional mission and values, and fostering positive relations within and outside the organisation. Although leaders did not review quantitative measures related to the $3 \mathrm{WP}$, narratives were generated about its positive influence on families and their dying loved ones, and on making work meaningful for staff. Narratives enhance the persuasiveness and memorability of health-related messages. ${ }^{26-28}$ Although contextual, ${ }^{29}$ narratives can have a compelling influence on health policy, ${ }^{3031}$ as exemplified by the leadership decisions in two centres to allocate funds to support programme expansion. ${ }^{17}$

The $3 \mathrm{WP}$ was viewed by managers and administrators as conferring considerable value for a modest cost. The distinction between cost and value is critical for healthcare leaders. Highcost interventions may provide good value because they are beneficial; conversely, low-cost interventions may have low or no value if they provide little benefit. Interventions providing minimal or no benefit typically have low value regardless of the cost. The low cost of the $3 \mathrm{WP}$ was facilitated by the leadership of front-line staff, integrating it into existing clinical workflow, volunteer assistance, donations, and the primarily free or inexpensive wishes (average of US\$5/wish). ${ }^{17}$

Our results highlight how managers and administrators are concerned about whether employees derive a sense of purpose from work, and how they conceptualise engagement in the $3 \mathrm{WP}$ as an opportunity to build resilience, feel inspired or even thrive at work. Some may consider it paradoxical that an end-of-life programme is congruent with IHI's fourth aim: improving the work life of healthcare providers. ${ }^{3}$ Leaders, however, seem to understand how dignifying the dying process can be rewarding, consistent with professional values. Previous findings from single-centre ${ }^{32}$ and multicentre ${ }^{17}$ studies confirm that clinicians themselves reported pride and meaning in their vocation when involved with the 3 WP. Other literature suggests that fostering clinicians' ability to make a difference and connect with others, both common activities in the $3 \mathrm{WP}$, has been linked to meaningful work. ${ }^{33}$ Some wishes require the engagement or endorsement of the larger institutional body, such as free parking passes, pet-friendly policies or permitting staff technicians to perform ultrasounds of a baby's heart beat at the bedside of a dying grandparent-to-be. These represent wishes that are concrete ways for clinicians to experience institutional values in their everyday job, contributing to more meaningful work. ${ }^{34}$

We used qualitative methods to obtain more contextual data than that which would be generated through a self-administered survey. We sought leadership views across four centres, ranging from those quite familiar with the programme (eg, longer duration of exposure, observation from a distance, or receipt of family or staff feedback) to leaders less familiar with the programme (eg, with shorter or very indirect exposure). This provided insight into the decision-making influences of hospital leaders in determining the value of programmes for an organisation.

Limitations of this study include no measure of family satisfaction or grief, or staff resilience or attrition. We previously reported the perspectives of nurses and physicians on how the 3 WP facilitates meaningful end-of-life care and favourably impacts the clinicians' sense of teamwork and the family experience $^{32}$; however, our focus was on hospital leaders in this study. We did not elicit critical comments when explicitly asking hospital leaders about potential programme downsides, raising the spectre of sampling bias. However, negative comments would likely have been forthcoming if the $3 \mathrm{WP}$ was unfavourably experienced.

\section{CONCLUSIONS}

Hospital leaders' perceived value of the $3 \mathrm{WP}$ was related not only to improved patient and family experiences, but also enhanced staff morale, alignment with the hospital mission and positive external public relations. When reflecting on this palliative care programme, clinical managers and senior administrators emphasised that their decision-making processes were influenced by the importance of narratives that promote institutional priorities. In this study, leaders underscored the need to balance the value that a programme brings with the resources it requires, stating how different types of evidence influence their support of new clinical programmes introduced into the hospital.

\section{Author affiliations}

'Department of Health Research Methods, Evidence, and Impact, McMaster University, Hamilton, Ontario, Canada

${ }^{2}$ Department of Family Medicine, McMaster University, Hamilton, Ontario, Canada ${ }^{3}$ Department of Medicine, Division of General Internal Medicine, Palliative Care

Program, University of California Los Angeles, Los Angeles, California, USA

${ }^{4}$ Department of Medicine, Division of Pulmonary and Critical Care, University of

California Los Angeles, Los Angeles, California, USA

${ }^{5}$ Critical Care Department, St Michael's Hospital, Toronto, Ontario, Canada

${ }^{6}$ Department of Nursing, Vancouver Coastal Health Authority, Vancouver, British Columbia, Canada

${ }^{7}$ Department of Critical Care, Vancouver Coastal Health Authority, Vancouver, British Columbia, Canada

${ }^{8}$ Department of Critical Care, St Joseph's Healthcare Hamilton, Hamilton, Ontario, Canada

${ }^{9}$ Department of Palliative Care, St Joseph's Healthcare, Hamilton, Ontario, Canada

${ }^{10}$ Department of Spiritual Care, St Joseph's Healthcare Hamilton, Hamilton, Ontario, Canada

${ }^{11}$ Department of Medicine, McMaster University, Hamilton, Ontario, Canada

\section{Twitter Alyson Takaoka @3wishesproject_}

Acknowledgements We acknowledge the interprofessional teams who implemented the 3 Wishes Project at each centre, and the patients and families who participated in the programme.

Contributors MS, MV, PP and DJC designed the study. THN, PP, OMS, ABa, ALB DF, VD, FJC, NH, AW, ABo, FT and DJC implemented the programme and collected quantitative and logistical data. MV, MS, OMS, PP and THN conducted the interviews and focus groups. All authors contributed to data analysis, led by MV, DJC, AT, MS and FJC. MS drafted the manuscript, with assistance from DJC, MV, PP and AT. All authors critically revised and approved the final manuscript.

Funding This work was peer review funded by a grant from The Greenwall Foundation and the Hamilton Academic Health Sciences Organization.

Competing interests None declared.

\section{Patient consent for publication Not required.}

Ethics approval Research ethics approval was obtained at each institution which implemented the 3 Wishes programme as a research project: Hamilton Integrated Research Ethics Board 1562 (St Joseph's Healthcare Hamilton); University of British Columbia Clinical Research Ethics Board H17-02290 (Vancouver General Hospital); St Michael's Hospital Research Ethics Board 16-183 (St Michael's Hospital); and UCLA Human Research Protection Program 17-001422 (Ronald Reagan Medical Center).

Provenance and peer review Not commissioned; externally peer reviewed.

Data availability statement No data are available. The qualitative data sets generated during the current study are not publicly available due to the potentially identifying nature of the complete qualitative transcripts and lack of consent from participants to publicly share these data.

Open access This is an open access article distributed in accordance with the Creative Commons Attribution Non Commercial (CC BY-NC 4.0) license, which permits others to distribute, remix, adapt, build upon this work non-commercially, and license their derivative works on different terms, provided the original work is properly cited, appropriate credit is given, any changes made indicated, and the use is non-commercial. See: http://creativecommons.org/licenses/by-nc/4.0/.

\section{ORCID iD}

Alyson Takaoka http://orcid.org/0000-0003-1442-080X 
Original research

\section{REFERENCES}

1 Berwick DM, Nolan TW, Whittington J. The triple aim: care, health, and cost. Health Aff 2008;27:759-69.

2 Bodenheimer T, Sinsky C. From triple to quadruple aim: care of the patient requires care of the provider. Ann Fam Med 2014;12:573-6.

3 Sikka R, Morath JM, Leape L. The quadruple aim: care, health, cost and meaning in work. BMJ Qual Saf 2015;24:608-10.

4 Pratt M, Ashforth B, Cameron K, et al. Fostering meaningfulness in working and at work. San Francisco: Berrett-Koehler Publishers, 2003.

5 Dik BJ, Steger MF, Fitch-Martin AR, et al. Cultivating Meaningfulness at Work. In: Hicks JA, Routledge C, eds. The experience of meaning in life: classical perspectives, emerging themes, and controversies. Dordrecht. Springer Netherlands, 2013: 363-77.

6 Lysova El, Allan BA, Dik BJ, et al. Fostering meaningful work in organizations: a multilevel review and integration. J Vocat Behav 2019;110:374-89.

7 Perlo J, Balik B, Swensen S, et al. IHI framework for improving joy in work. Cambridge, Massachusetts: Institute for Healthcare Improvement, 2017.

8 McHugh MD, Kutney-Lee A, Cimiotti JP, et al. Nurses' widespread job dissatisfaction, burnout, and frustration with health benefits signal problems for patient care. Health Aff 2011;30:202-10.

9 Rushton $\mathrm{CH}$, Batcheller J, Schroeder K, et al. Burnout and resilience among nurses practicing in high-intensity settings. Am J Crit Care 2015;24:412-20.

10 Landon BE, Reschovsky JD, Pham HH, et al. Leaving medicine: the consequences of physician dissatisfaction. Med Care 2006;44:234-42.

11 Oreskovich MR, Shanafelt T, Dyrbye LN, et al. The prevalence of substance use disorders in American physicians. Am J Addict 2015;24:30-8.

12 Pompili M, Innamorati M, Narciso V, et al. Burnout, hopelessness and suicide risk in medical doctors. Clin Ter 2010;161:511-4.

13 Shanafelt TD, Balch CM, Dyrbye L, et al. Special report: suicidal ideation among American surgeons. Arch Surg 2011;146:54-62.

14 Shanafelt TD, Gradishar WJ, Kosty M, et al. Burnout and career satisfaction among US oncologists. J Clin Oncol 2014;32:678-86.

15 Shanafelt T, Goh J, Sinsky C. The business case for investing in physician well-being. JAMA Intern Med 2017;177:1826-32.

16 Cook D, Swinton M, Toledo F, et al. Personalizing death in the intensive care unit: the 3 wishes project: a mixed-methods study. Ann Intern Med 2015;163:271-9.
17 Vanstone M, Neville TH, Clarke FJ, et al. Compassionate end-of-life care: mixed-methods multisite evaluation of the 3 wishes project. Ann Intern Med 2020;172:1-12.

18 Crotty M. The foundations of social research: meaning and perspective in the research process. SAGE, 1998.

19 Sandelowski M. What's in a name? qualitative description revisited. Res Nurs Health 2010;33:77-84.

20 Neergaard MA, Olesen F, Andersen RS, et al. Qualitative description - the poor cousin of health research? BMC Med Res Methodol 2009;9:52.

21 Hsieh H-F, Shannon SE. Three approaches to qualitative content analysis. Qual Health Res 2005;15:1277-88.

22 Sandelowski M. Whatever happened to qualitative description? Res Nurs Health 2000;23:334-40

23 Vaismoradi $\mathrm{M}$, Turunen $\mathrm{H}$, Bondas T. Content analysis and thematic analysis: implications for conducting a qualitative descriptive study. Nurs Health Sci 2013;15:398-405

24 Patton MQ. Qualitative research \& evaluation methods. SAGE, 2002.

25 Rodgers BL, Cowles KV. The qualitative research audit TRAIL: a complex collection of documentation. Res Nurs Health 1993:16:219-26.

26 Shen F, Sheer VC, Li R. Impact of narratives on persuasion in health communication: a meta-analysis. J Advert 2015;44:105-13.

27 Stone D. Policy paradox: the art of reason. 1 edn. Scott Foresman \& Co, 2011

28 Jones MD, McBeth MK, Shanahan EA, et al. Introducing the Narrative Policy Framework. In: The science of stories: applications of the narrative policy framework in public policy analysis. New York: Palgrave Macmillan US, 2014.

29 Fadlallah R, El-Jardali F, Nomier M, et al. Using narratives to impact health policymaking: a systematic review. Health Res Policy Syst 2019;17:26.

30 Jones MD, McBeth MK. A narrative policy framework: clear enough to be wrong? Policy Stud J 2010;38:329-53.

31 Shanahan EA, Jones MD, McBeth MK. Policy narratives and policy processes. Policy Stud J 2011;39:535-61.

32 Neville TH, Agarwal N, Swinton M, et al. Improving end-of-life care in the intensive care unit: clinicians' experiences with the 3 wishes project. J Palliat Med 2019;22:1561-7.

33 Pavlish C, Hunt R. An exploratory study about meaningful work in acute care nursing. Nurs Forum 2012;47:113-22.

34 Carton AM. "I'm not mopping the floors, I'm putting a man on the moon": how NASA leaders enhanced the meaningfulness of work by changing the meaning of work. Adm Sci Q 2018:63:323-69. 